\title{
Platform-centric Modular Service Architecture Design KIBS-oriented Based on Front-Back Stage Decoupling
}

\author{
Zhenkun Zhou \\ Department of finance and economics \\ Shenzhen Institute of Information Technology \\ Shenzhen, Guangdong Province, China \\ zhouzk77@gmail.com
}

\author{
Yong Lin \\ Business School \\ University of Greenwich \\ London, UK \\ yonglin1212@gmail.com
}

\begin{abstract}
Balancing customization and standardization in knowledge intensive business services is the dilemma issue of the success trade-off between efficiency and cost. This paper develops modular service platform architecture for KIBS firms who are thinking simultaneously various kinds of dynamic relationships containing niche market strategies, platform-centric tactics and operational means of core capabilities matching in the context of service innovation. Two-dimension front-back stage decoupling views on modular service architecture are identified, that is one by the object dimension in the front stage for splitting abstract and virtual service requirements, the other one by the delivery dimension in the back stage for deploying specific service organization and visual service procedures. This new theoretical framework is proposed to help further studies on service modularization design in KIBS.
\end{abstract}

Keywords-Service design; Service modularization; Front and back stage de-coupling; Platform strategy; KIBS

\section{INTRODUCTION}

Knowledge intensive business services (KIBS) firms are enterprises whose primary value-added activities consist of the accumulation, creation, or dissemination of knowledge for the purpose of developing a customized service [1]. Examples of KIBS firms are technical engineering services, management consultancy, software and information processing services, research and development, marketing and media services; third and fourth party logistics service providers [2]. The main challenge for KIBS is to balance between the ability of adapting to individual customers' needs and, at the same time, the ability of serving several customers. The concept of service architecture may come in useful to tackle this issue, drawing particularly on the idea of modular architecture because it enables customization and standardization to be achieved at one and the same time [3].

Meanwhile, Chen [4] has proposed decision-making methods for front and back stage decoupling based on mass customization. The front end is the first portion of the development effort, and consists of the activities involved in determining what service concept should be developed. The back-end is the remaining portion of the development effort, and consists of activities involved in actually implementing the chosen service concept. The front end (which is classically Marketing-centric) can become isolated from the back-end (which is classically Operations-centric), leading to "over-thewall" transfer of information and other dysfunctional organizational behavior [5].

The remainder of this paper is organized as follows: literature review, methodology, findings and discussions, and conclusions. Literature review concentrates on two specific topics; one is service architecture and service platform, the other one is front-back stage decoupling. Methodology specifies the case study research method and the conceptual framework. Findings are summarized and analyzed based on case study of KIBS provider in China. Implications, limitations and future research directions are summarized in conclusions.

\section{LITERATURE REVIEW}

\section{A. The relationship between service architecture and service platform}

Voss and Hsuan define service architecture as the way that the functionalities of the service system are decomposed into individual functional elements to provide the overall services delivered by the system [3]. In exploring the architecture of services, they restrict it to the examination of four levels, even though it may be possible to subdivide into many more than these four. The levels are as follows: industry, service company/supply chain, service bundle, and service package/component.

Pekkarinen, and Ulkuniemi developed modular service platform including four modularity dimensions: service, process, organizational and customer interface dimensions can be used to create value in business services [6]. Lin and Pekkarinen build a conceptual research framework and this research expands the four dimensions proposed in Pekkarinen and Ulkuniemi [6] to five, which are service, process, organization, customer interface and activity [7]. Zhou et al. develop a service platform for the IT companies, who are serviceoriented and build four levels as follows: service context, service configuration, service capability and service component [8]. 
Overall, Voss and Hsuan represented by authors apply the concept called the term "service architecture" to construct an empirically grounded model, while this term called the term "service platform" is established in Pekkarinen, and Ulkuniemi represented by research framework. Baldwin and Woodard think it is crucial to understanding the relationship between platforms and architecture as well as the nature of platforms clearly, hence the dynamics of platform-based innovation and competition. However, which has received little attention up to now [9]. Therefore, what on earth the platform-centric service architectures focus on in such a variety of KIBS contexts?

\section{B. The development of fron -back stage decoupling views on KIBS and service moularity}

Sundbo classified the development mode of service enterprises into standardized, modularized, and customized in the report of SI4S [10]. Wei et al. investigate that KIBS is continuous spectra from standardized, modularized to customized ones. Knowledge intensive could be manifested in four aspects: tacit knowledge dominance, technical management complexity, high degree of customer contact and continuous innovation [11]. Therefore, for most KIBS firms, on the one hand, the ability of adapting to individual customers' needs calls for service customization, while on the other the ability of serving several customers requires greater problem-solving capabilities and service standardization to obtain economies of scale and scope.

The visionary view of front-back stage decoupling was first coined by Thompson [12]. Chase succeeded these viewpoints and proposed that back-office work should be segregated from front-office work. In addition, the front stage is the part in service system where activities that require customer contact take place and as such is directly experienced by customers, whereas the back stage contains processes that are carried out remotely from customers and hence cannot be seen or experienced by customers [13].

Both the practices and theoretical researches for front and back stage decoupling concept entered a new stage of evolution. To overcome the operating dilemma of trade-off between efficiency and cost, Li et al. explained that optimization should be conducted along the two dimensions. In the object dimension, optimization could be achieved from the thorough analysis of the relationship among the products and their elements (atoms, elements, modules, etc.). While in the process dimension, re-arrangement of production process and resources in each stage could be beneficial to optimization purposes [14]. In the two-dimension, most of literatures agreed that modularity would be the key [15]. Even the KIBS literatures, which traditionally emphasize the customized nature of KIBS, has recently made the point that KIBS might adopt modular approaches [16], especially apply service modularization approaches [17].

This shows that the concept of front-back stage decoupling may come in useful to tackle the operating dilemma of KIBS, drawing particularly on the idea of modular architecture because it enables customization and standardization to be achieved at one and the same time. However, how to design and deploy front /back stage configuration structure by applying the service modularization logic in KIBS context?

\section{METHODOLOGY}

Before based on the literature review, this research on service architecture design aims to discuss the dilemma issue of KIBS with modularity and platform-centric views, and to identify the operational mechanism with front-back stage decoupling approach. More specifically, this paper aims to answer the following two research questions:

RQ1. What relationship between service platforms and service architecture?

RQ2. How to design and deploy front /back stage configuration structure by applying the service modularization logic?

Case study [18] is adopted for this research to answer the research questions with a contemporary nature. The research defines the case as a KIBS provider offering information technology services. Data are collected from interview, official websites, news, and other secondary documentary.

\section{FINDINGS AND DISCUSSIONS}

The research results are mainly derived from analyzing the data collected from three leading KIBS firms namely information technology service, software development service, and ERP implement service in China, meanwhile deepen and extend the findings of these three related papers namely Ma et al. [19], Zhou et al.[20],[21], and Lin et al. [22]in several ways. Finally, studies are summarized and concluded into a framework.

\section{A. Front-end stage design}

Front office (FO) of service platform architecture design based-on the object dimension answers the question of what needs to be done. That is, one must clearly segment customer groups, understand user needs in target segments, and design effective solutions. The modularization of FO could be utilized for construction of the "virtual" modular structure based on service concept [23]. This special "virtual" modular structure is constructed sequentially by service bundle, service module, and service component. Each service bundle can be viewed as a set of service modules, and the service component is the smallest building block of service platform architecture when viewed from service contents and core function perspective. Each service component could be divided into two categories namely standard service component and unique service component [8]. Mix-and-match varigrained modules including service bundle, service module, and service component as well as integration of shared service architecture, and embodied design rules is arguably the most difficult yet important challenge facing KIBS firms seeking niche markets (See Figure $1)$. 


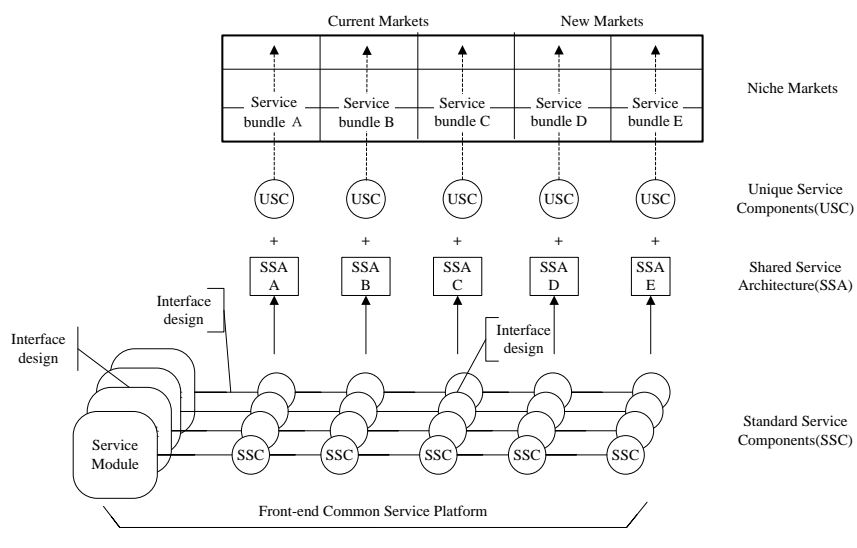

Figure 1. FO design based-on the object dimension

\section{B. Back-end stage design}

After identifying target market segments and developing a suitable service concept to address the target market's needs, next comes creating an operation strategy to support the service concept and designing a modular service network to support the operation strategy. Back office (BO) of service platform architecture design based-on the delivery dimension absolutely answers the question of how and where things will be done. In contrast to FO, The modularization of $\mathrm{BO}$ could be utilized for construction of the "visual" process module based on delivery innovation [23] and specified organization module. Process modules refer the satisfiers that are what needs to be done to fulfill the customer's order. In most case, service modules/components are visible to the end-customer, while process modules are only visible to the internal customer (including partners). Each process module could be separated into several activity modules in sequence. That is, the process module subsequently consists of several activity modules. A activity module is defined as a standardized, not further divisible, process step. Mix-and-match varigrained modules including process module and activity module as well as integration of organization modules and interfaces design is effective means for KIBS firms matching their dynamic capabilities (See Figure 2).

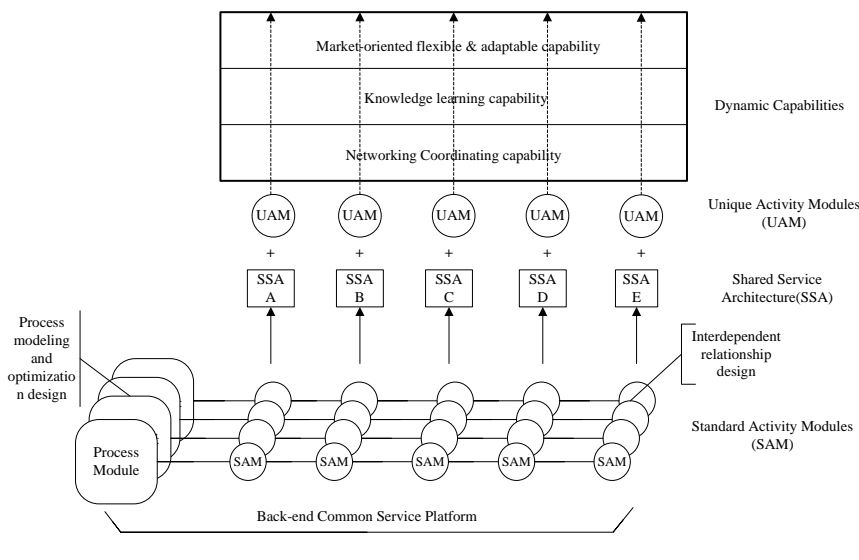

Figure 2. BO design based-on the delivery dimension

\section{Platform-centric Modular Service Architecture Design}

According to Baldwin and Woodard [9], platform-centric service architecture of this paper could be identified that it is modularizations of complex systems in which certain components (the platform itself) remain fixed over the life of the platform, while others (the complements) are encouraged to vary in cross-section or change over time. Its design will also similarly incorporate five basic principles according to Meyer and detore [16]:

1) Common service platform span multiple service components (from front-end stage) or activity modules (from back-end stage) that are implemented with common service modules (from front-end stage) or process modules (from backend stage) and all kinds of service interfaces [19].

2) Modular approach inclding service modularity, process modularity and organization modularity is applied to platform development [6].

3) A third and equally essential principle of platform thinking is that a new platform should have the capability to address new market in the special service context by mix-andmatch standard service components and embedding unique service components [8], as well as reuse and sharing of the core modules of platform.

4) A fourth principle of platform thinking is that common service platform, service modules/components, process/activity modules, and interfaces all have within them deeper insights, which comprises a corporation's dynamic capabilities in the areas of market-oriented flexible \& adaptable capability, knowledge learning capability, and networking coordinating capability.

5) A fifth and last principle of platform thinking is that service modularity and process modularity have important implications for the organizational design of the enterprise. Organizational modules are emerged into internal resources modules and external resources modules. The former involves three themes: dynamic team, competence area, and knowledge area. The last one includes subcontracting, hired labor, and partnership arrangements.

The results are listed in table 1 and illustrated with figure 3 containing some critical views on the relationship of service architecture and service platform.

TABLE I. THE RELATIONSHIP BETWEEN SERVICE ARCHITECTURE AND SERVICE PLATFORM

\begin{tabular}{|l|l|l|}
\hline & \multicolumn{1}{|c|}{ Definition } & \multicolumn{1}{c|}{ Research perspective } \\
\hline \multirow{4}{*}{$\begin{array}{l}\text { Service } \\
\text { architecture }\end{array}$} & $\begin{array}{l}\text { An abstract description of } \\
\text { the entities of a system } \\
\text { and how they are related } \\
{[24] .}\end{array}$ & $\begin{array}{l}\text { 1.service context (FO) } \\
\text { 2.service component (FO) } \\
\text { 3.service configuration (FO/BO) } \\
\text { 4.service capability (BO) }\end{array}$ \\
\hline $\begin{array}{l}\text { Service } \\
\text { platform }\end{array}$ & $\begin{array}{l}\text { It is the architecture of the } \\
\text { system that enables other } \\
\text { features to be added or } \\
\text { existing features to be } \\
\text { removed [25]. }\end{array}$ & $\begin{array}{l}\text { 1.service modularity (FO) } \\
\text { 3.organization modularity (BO) } \\
\text { 4.interfaces (FO/BO) }\end{array}$ \\
\hline
\end{tabular}




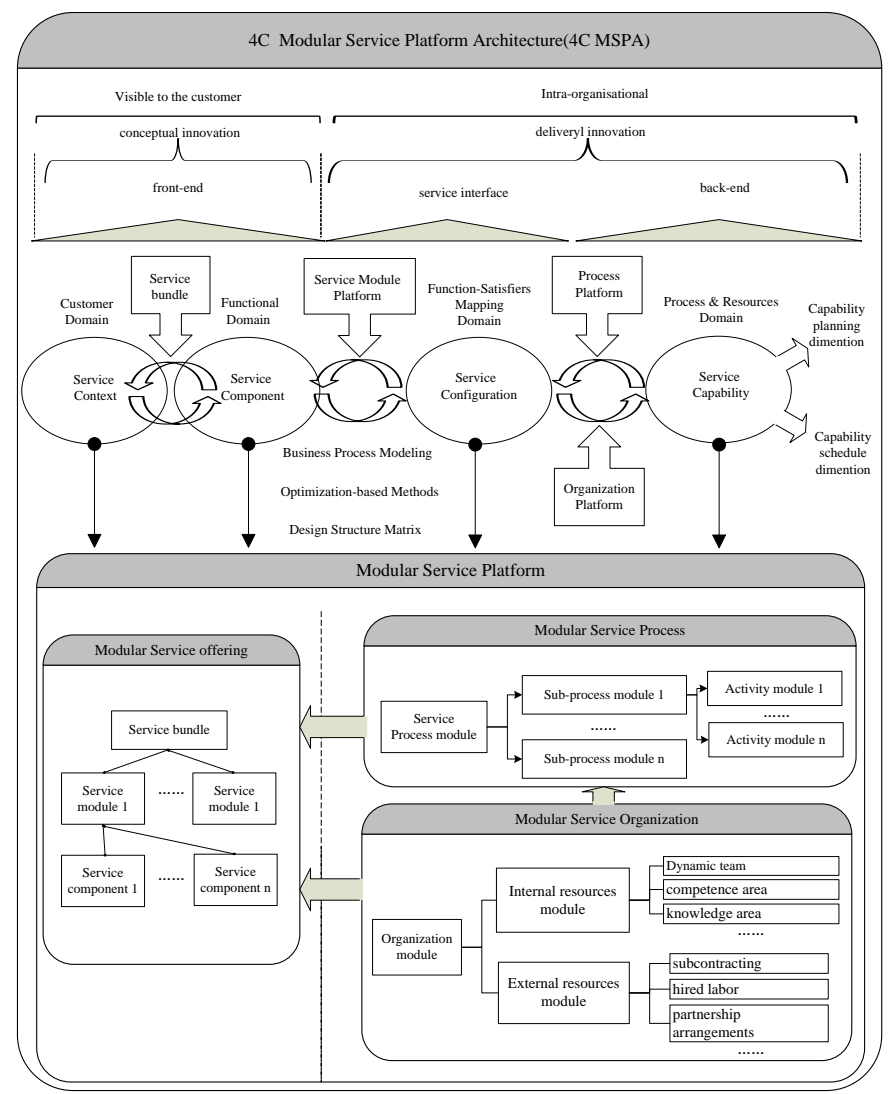

Figure 3. Platform-centric Modular Service Architecture based-on forntback stage decoupling

\section{CONCLUSION}

This paper extends the service modularization research in KIBS context with platform thinking and front-back stage decoupling approach. The proposed framework helps the practitioners nurture and evolve their modular platform architecture. Further case studies and empirical testing of the research results and the proposed framework will be performed in the future in order to further validate and strengthen its generality.

\section{ACKNOWLEDGMENT}

This paper benefited from the many insightful comments made by the three anonymous reviewers of IEEE International Conference on Software Engineering and Service Science. The author would also like to thank Dr Yong Lin, Professor Shihua $\mathrm{Ma}$, and Mr. Feng Yue for the comments and suggestions they made on previous version of the manuscript.

\section{REFERENCES}

[1] L. A. Bettencourt, A. L. Ostrom, S. W. Brown, and R. I. Roundtree, "Client Co-Production in Knowledge-Intensive Business Services.," California Management Review, vol. 44, pp. 100 - 128, 2002.

[2] I.Miles, "Knowledge intensive business services: prospects and policies," foresight, vol. 7, pp. 39 - 63, 2005.

[3] C. A. Voss and J. Hsuan, "Service Architecture and Modularity," Decision Sciences, vol. 40, pp. 541-569, 2009.
[4] J. Chen, "De-coupling of front-back stages in service industries:developments from traditional operation to mass customization," African Journal of Business Management, vol. 5, pp. 11727-11735, 2011.

[5] L. J. Menor, M. V. Tatikonda and S. E. Sampson, "New service development: areas for exploitation and exploration," Journal of Operations Management, vol. 20, pp. 135-157, 2002.

[6] S. Pekkarinen and P. Ulkuniemi, "Modularity in developing business services by platform approach," The International Journal of Logistics Management, vol. 19, pp. 84-103, 2008.

[7] L. Yong and S. Pekkarinen, "QFD-based modular logistics service design," Journal of Business \& Industrial Marketing, vol. 26, pp. 344356, 2011.

[8] Z. Zhou, Y. Lin, S. Ma, and F. Yue, "Modularity of service design for IT company," in Service Operations and Logistics and Informatics (SOLI), 2010 IEEE International Conference on Qingdao, Shandong, 2010, pp. 136-141.

[9] C. Y. Baldwin, C. J. Woodard and Others, "The architecture of platforms: A unified view," Platforms, markets and innovation, pp. 19-44, 2009.

[10] Sundbo, "Modulization of Service Production and a Thesis of Convergence Between Service and Manufacturing Organizations," Scandinavian Journal of Management, vol. 10, pp. 245-266, 1994.

[11] J. Wei, Y. Tao and L. Wang, "The concept and classification of knowledge-intensive business service," China Soft Science, vol. 1, pp. 33-41, 2007 (in Chinese).

[12] J. D. Thompson, Organizations in Action.Social Science Bases of Administrative Theory: McGraw-Hill, New York, NY., 1967.

[13] R. B. Chase, "Where Does the Customer Fit in a Service Operation," Harvard Business Review, vol. 56, pp. 137-142, 1978.

[14] Li SC, Liang GQ, Liu CG (2003). The Theory of Mass Customization Operation, Science Publishing House: Beijing (in Chinese).

[15] D. Campagnolo and A. Camuffo, "The concept of modularity in management studies: A literature review," International Journal of Management Reviews, pp. 1-28, 2009.

[16] M. H. Meyer and A. Detore, "Perspective: Creating a platform-based approach for developing new services," Journal of Product Innovation Management, vol. 18, pp. 188-204, 2001.

[17] R. Dorbecker and T. Bohmann, "The Concept and Effects of Service Modularity -- A Literature Review," in System Sciences (HICSS), 2013 46th Hawaii International Conference on Hawaii, 2013, pp. 1357-1366.

[18] R. K. Yin, Case study research:design and methods(Chinese 2th edition). Chongqing: Chongqing University Press, 2010.

[19] M. Shihua, Z. Zhou, Y. Lin, and F. Yue, "Modularity Service Platform Design Based on BOM," Industrial Engineering and Management, pp. 5$11+17,2011$.

[20] Z. Zhou, M. Shihua, L. Yong, and Y. Feng, "Multi-Objective Optimization for Modular ERP Implementation Service Design," Chinese Journal Of Management, pp. 1368-1374, 2013.

[21] Z. Zhou, "Design of Object-oriented Modular Teledata Collection System Requirements," Computer and Modernization, pp. 233-238, 2013.

[22] L. Yong, Z. Zhenkun, Z. Li, and M. Shihua, "ERP Implementation Service Supply Chain:A Modular Perspective," in E-Logistics and ESupply Chain Management:Applications for Evolving Business: IGI GLOBAL PROOF, 2013, pp. 274-288.

[23] W. Jiang, W. Lin, H. Shengrong, and T. Yan, "the typology of innovation in knowledge-intensive business service," Studies in Science of Science, vol. 26, pp. 196-241, 2008.

[24] D. E. Whitney, E. Crawley, O. de Weck, S. Eppinger, C. Magee, J. Moses, W. Seering, J. Schindall, and D. Wallace, "The Influence of Architecture in Engineering Systems,": Engineering Systems Monograph, MIT, Cambridge, MA (March), 2004.

[25] S. C. Wheelwright and K. B. Clark, "Creating project plans to focus product development," Harvard Business Review, vol. 70, pp. 67-83, 1992. 